
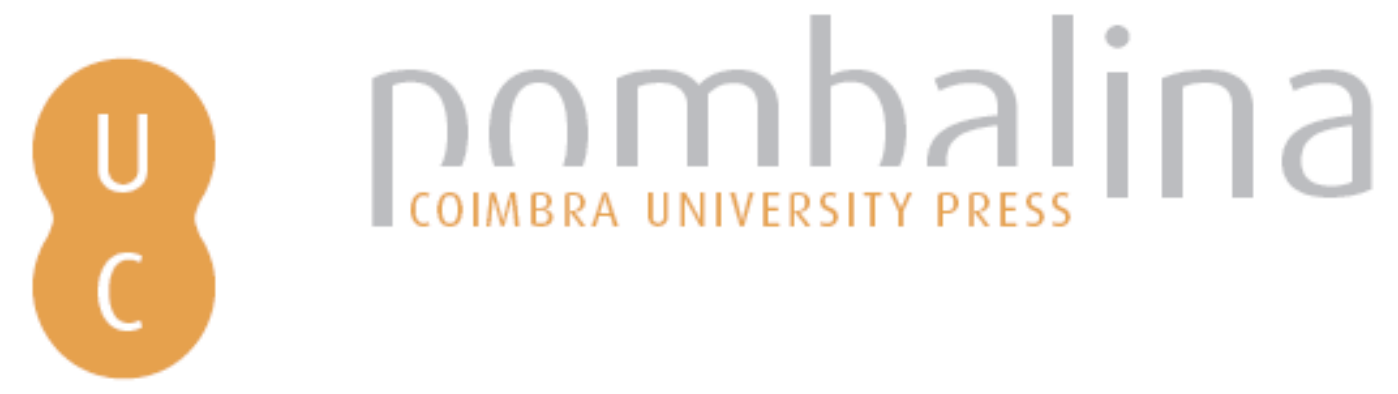

\title{
Inovação-tradição-globalização: as ciências modernas à descoberta do mundo: mapeando a natureza brasílica nas rotas dos mares do sul
}

Autor(es): $\quad$ Janeira, Ana Luísa; Borralho, Luísa; Fortes, Mário

Publicado por: Imprensa da Universidade de Coimbra

URL

persistente:

URI:http://hdl.handle.net/10316.2/32447

DOI:

DOI:http://dx.doi.org/10.14195/978-989-26-0469-5_37

Accessed : $\quad$ 26-Apr-2023 11:41:17

A navegação consulta e descarregamento dos títulos inseridos nas Bibliotecas Digitais UC Digitalis, UC Pombalina e UC Impactum, pressupõem a aceitação plena e sem reservas dos Termos e Condições de Uso destas Bibliotecas Digitais, disponíveis em https://digitalis.uc.pt/pt-pt/termos.

Conforme exposto nos referidos Termos e Condições de Uso, o descarregamento de títulos de acesso restrito requer uma licença válida de autorização devendo o utilizador aceder ao(s) documento(s) a partir de um endereço de IP da instituição detentora da supramencionada licença.

Ao utilizador é apenas permitido o descarregamento para uso pessoal, pelo que o emprego do(s) título(s) descarregado(s) para outro fim, designadamente comercial, carece de autorização do respetivo autor ou editor da obra.

Na medida em que todas as obras da UC Digitalis se encontram protegidas pelo Código do Direito de Autor e Direitos Conexos e demais legislação aplicável, toda a cópia, parcial ou total, deste documento, nos casos em que é legalmente admitida, deverá conter ou fazer-se acompanhar por este aviso.

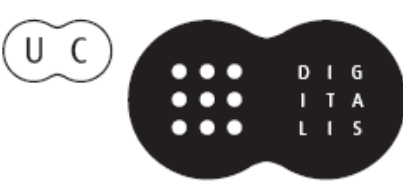


Ana Leunar Pereira João Rui Pita

[ Coordenaçä̃ ]
Rotas da Natureza

Cientistas

Viagens

Expedifgũes

Instituip̧ües

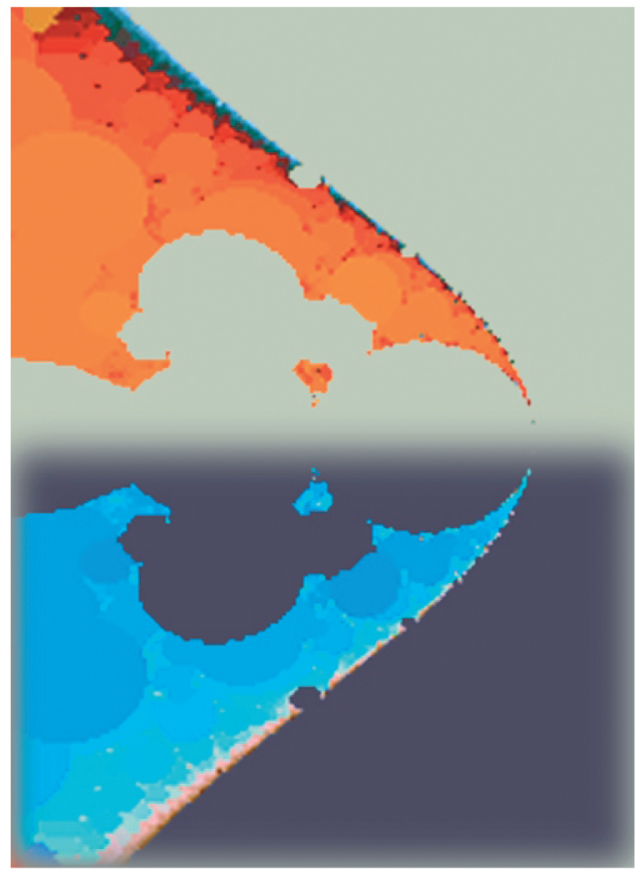




\section{Coordenaçáo Científica da Colecção Ciências e Culturas}

João Rui Pita e Ana Leonor Pereira

Os originais enviados são sujeitos a apreciação científica por referees

\section{Coordenação Editorial}

Maria João Padez Ferreira de Castro

\section{Edição}

Imprensa da Universidade de Coimbra

Email:impresauc@ci.uc.pt

URL: http://www.imp.uc.pt • Normas de publicação de colecçôes

\section{Design}

António Barros

Pré-Impressáo

António Resende

Imprensa da Universidade de Coimbra

\section{Capa}

António Barros, com imagem de E. M. de Melo e Castro, 2003 [Fractal original gerado no Fractint com tratamento no Photoshop 7.0]; Cortesia: António Barros

Impressão e Acabamento

SerSilito • Maia

\section{ISBN}

978-989-8074-12-6

\section{Depósito Legal}

Obra publicada com a colaboraçáo de:
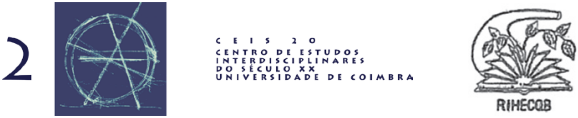

Obra publicada com o apoio de:

FCT Fundação para a Ciência e a Tecnologia

MINISTÉRIO DA CIÊNCIA, TECNOLOGIA E ENSINO SUPERTOR Portug

Programa Operacional Ciência, Tecnologia, Inovação do Quadro Comunitário de Apoio III
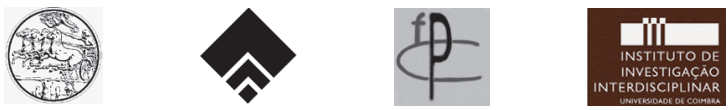

\section{Baxter}

(c) 2006, Imprensa da Universidade de Coimbra 
João Rui Pita

Ana Leonar Pereira

(Courdenação)

Rotas da Natureza

Cientistas

Viagens

Expediçũes

Instituiç̃̃es

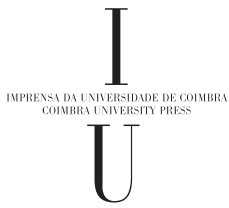

- colmbra 2006 
(Página deixada propositadamente em branco) 


\author{
Ana Luísa Janeira*; Luísa Borralho** ; Mário Fortes** \\ * Departamento de Química e Bioquímica da Faculdade de Ciências da Universidade de Lisboa; Centro \\ Interdisciplinar de Ciência, Tecnologia e Sociedade da Universidade de Lisboa (CICTSUL), Portugal \\ ** Arquitectos Paisagistas, Portugal
}

\author{
INOVAÇÃO-TRADIÇÃO-GLOBALIZAÇĀO. \\ AS CIÊNCIAS MODERNAS À DESCOBERTA DO MUNDO. \\ MAPEANDO A NATUREZA BRASÍlICA \\ NAS ROTAS DOS MARES DO SUL
}

A bibliografia tem enaltecido a qualidade da iconografia europeia, logo nos primeiros contactos com as riquezas naturais brasileiras. Isso acontecendo quando os exemplares são autónomos, ou quando figuram como ilustrações de textos. Paralelamente, é comum lamentar-se a ausência deste tipo de informações por parte dos portugueses, em períodos similares.

A desproporção entre esta e aquela presença na magnífica exposição O Brasil dos Viajantes, apresentada no Centro Cultural de Belém, serviu para nos evidenciar uma questão, no meio de um certo mal-estar. Depois, motivados por algumas observaçôes, aquando da preparação da exposição $O \mathrm{Jardim}$ do Éden ${ }^{1}$, fomos revivendo a questão sem qualquer saída imediata, pelo que nos mantivemos dentro da linha interpretativa comum ${ }^{2}$.

Curiosamente, a invisibilidade documental pode reverter-se numa demanda fascinante.

Ao longo dos últimos meses, resolvemos explorar a seguinte hipótese de trabalho: perspectivar portulanos e cartas portugueses como complementares dos textos, quer dizer relevar o conhecimento da realidade natural brasileira a partir destas fontes.

$\mathrm{Na}$ verdade, parece importante aprofundar e aferir conexões entre o conhecimento dos Três Reinos da Natureza e as suas representações em mapas. Com isto, pretende-se contribuir para reduzir uma lacuna epistemológica e aumentar o número de estudos que relacionem a Cartografia com a História Natural.

\footnotetext{
${ }^{1}$ Os autores deste texto fizeram parte do Comissariado Científico da exposição O Jardim do Éden, prevista pela Comissão Nacional dos Descobrimentos Portugueses para o Mosteiro dos Jerónimos, 2000.

${ }^{2}$ Ana Luísa Janeira - «Todo o Brasil parece hü jardim». «Episteme», Porto Alegre, publicação prevista para Maio de 2003. Luísa Borralho, Mário Fortes - Descriçôes do Reino Vegetal - Do jardim do Éden às Terras de Vera Cruz, «Episteme», Porto Alegre, publicação prevista para Maio de 2003.
} 


\section{A iconografia europeia de Vera Cruz}

A desproporção entre a presença portuguesa diminuta e a presença maciça de outros europeus na magnífica exposição O Brasil dos Viajantes, apresentada no Centro Cultural de Belém, em Lisboa, serviu para mostrar uma realidade com certo mal-estar.

Durante a preparação da exposição $O \mathrm{Jardim}$ do $E^{\prime} d e n^{3}$, a questão foi revivida sem qualquer saída imediata, pelo que prevaleceu a linha interpretativa comum ${ }^{4}$.

Mas ao longo dos últimos meses, começámos a explorar uma hipótese de trabalho inovadora: perspectivar portulanos e cartas como testemunhos informativos complementares para as Ciências da Natureza em Portugal e no Brasil. Ou seja, avaliar a cartografia portuguesa relativamente ao conhecimento da realidade natural brasileira. Atitude que se alicerça numa demanda onde se interceptam a Filosofia das Ciências, procurando desbloquear vazios e alargar o alcance testemunhal das fontes para a História das Ciências, e a Arquitectura Paisagista, indagando a constituição da natureza brasílica e a representatividade da sua Paisagem.

Quando interroga a tipologia das fontes que constituem o universo heurístico dominante, o questionamento filosófico evidencia como ainda não foi colmatada a lacuna epistemológica, criada pela falta de estudos que relacionem Cartografia e História Natural. Neste sentido, será importante iniciar uma abordagem, visando localizar, aferir e aprofundar nexos entre as representações nos mapas e o conhecimento dos Três Reinos da Natureza.

Apesar das novidades com que os europeus se depararam no Novo Mundo, - «e digam lá os sábios da Escritura, que segredos são estes da Natura» -, é indiscutível que a mentalidade vigente não estava preparada para tanta novidade, o que não lhes permitiu uma abordagem adequada, de imediato.

Para colmatar estas fragilidades, a imaginação e o simbólico intervieram, no sentido de dar uma maior solidez às posições. Por outras palavras, face à natura desconhecida - coisas nunca vistas -, a cultura intervém - paradigmas, modelos, regras -, como património a assegurar-lhes a convicção de uma supremacia, quer no contacto primário, quer na interpretação secundária. Assim, o legado cultural servia como cabedal de respostas aos desafios de uma envolvência recém-descoberta, interferindo na perceptibilidade do exterior.

Facto que nem sempre equivaleu à melhor estratégia, mas que correspondeu seguramente a estratégias possíveis.

Geralmente, as mudanças súbitas facilitam situaçōes opostas, ao ocorreram entre termos extremados: ou o recurso a um estilo pré-concebido, apesar de postiço para a situação nova - primeiro caso -; ou o recurso a um tempo de espera, tido por necessário à adaptação futura - segundo caso -.

Enquadramos os desenhos, pinturas e gravuras dos europeus não portugueses no primeiro caso - recurso a um estilo pré-concebido e postiço para a situação nova: as

\footnotetext{
${ }^{3}$ Os autores deste texto fizeram parte do Comissariado Científico da exposição O Jardim do Éden, prevista pela Comissão Nacional dos Descobrimentos Portugueses para o Mosteiro dos Jerónimos, 2000.

${ }^{4}$ Ana Luísa Janeira - «Todo o Brasil parece hü jardim». «Episteme», Porto Alegre, publicação prevista para Maio de 2003. Luísa Borralho, Mário Fortes - Descriçôes do Reino Vegetal - Do jardim do Éden às Terras de Vera Cruz, «Episteme», Porto Alegre, publicação prevista para Maio de 2003.
} 
magníficas frutas tropicais emergem entre céus e paisagens românticas ou neoclássicas, o traçado da ilustração em livros faz-se segundo cânones ao bom estilo tradicional.

Isto sendo possível, logo desde a chegada, apesar destes registos serem seguidos por muitos outros estilos, diversificados no tempo:

«O estudo da iconografia e da literatura produzidas pelos viajantes estrangeiros no decorrer do século XV ao XIX revela a mudança de enfoque do olhar sobre nossa gente, fauna e flora, constituindo uma revisão da imagem do país. A iconografia produzida no século XVI manifesta, muitas vezes, um processo de construção de imagens geradas pelas crônicas e não representações reais. Além de mostrar todo o exotismo da fauna e da flora, do ponto de vista do europeu, as obras foram responsáveis pela formação da imagem do índio americano. O canibalismo é cena freqüente desse imaginário. Durante o período de ocupação dos holandeses no Nordeste, entre 1636 e 1645, o governador Maurício de Nassau contratou uma comitiva de artistas, dentre os quais pintores e desenhistas, com o objetivo de registrar e documentar diferentes aspectos da vida brasileira. Nessa produção, destacam-se as paisagens que retratam vistas panorâmicas, portos e fortificações de Frans Post, e os tipos etnográficos e exóticos de Albert Eckhout.» 5

Como nota Nereide Santa Rosa ${ }^{6}$ : «Frans Post e Albert Eckhout foram os artistas holandeses que vieram junto com Mauricio Nassau.... Repare na amplidão dos espaços, nos detalhes, e no horizonte desta obra de Post [Paisagem com construção, sem data]. Parece até que os artistas usavam luneta para enxergar tão longe!

Eles foram considerados os primeiros paisagistas do Novo Mundo. Eles buscaram registrar o cotidiano de um país recém-descoberto pala Europa. O povo e seus costumes, os indígenas, e principalmente as paisagens tropicais, eram imagens exóticas para os olhares europeus. Repare no grupo de pessoas que aparece nesta obra de arte [Tropical Landscape, 1649], na sua postura, e até mesmo nas suas roupas. O artista não lhes dá destaque, ele está preocupado em inseri-las na paisagem. Vemos um critério amplo, com detalhes importantes como o horizonte, a vegetação, as palmeiras, elementos particularmente interessantes para os europeus.

No ano de 1644, Maurício de Nassau foi expulso pelos portugueses, e os artistas retornaram à Holanda, onde continuaram a pintar as lembranças que tinham do Brasil. As obras de arte desse período mostram representações do Brasil com uma certa dose de imaginação do artista, fruto das recordações de viagem. Além de serem influenciadas pelo Barroco, movimento artístico que predominava na Europa, nessa época.»

\section{A Natureza Brasileira na Cartografia Portuguesa}

Visibilidade equivale a existência? Verdadeiro. Invisibilidade significa inexistência no passado ou no presente? Falso. Logo, importa acrescentar: não ser/estar visível não quer dizer que não tenha existido, perdendo-se depois. Até poderá querer dizer que existe, está escondido, mas ainda não foi encontrado. No caso, ter sido destruído pelo

\footnotetext{
5 Site do Instituto Itaú Cultural

${ }^{6}$ Nereide Schilaro Santa Rosa - Cidades e Florestas: os artistas viajantes entre os séculos XVII e XIX. Rio de Janeiro, Edições Pinakotheke, 10-13.
} 
Terramoto de 1751. Ou permanecer perdido (Biblioteca Nacional de Lisboa, Biblioteca de Mafra, Biblioteca de Ajuda, Biblioteca do Escorial, Biblioteca Nacional do Rio de Janeiro, Biblioteca de França, etc.).

$\mathrm{Na}$ situação presente, e no que respeita a divulgação artística e científica, o comportamento dos portugueses parece enquadrável no segundo caso - recurso a um tempo de espera, tido por necessário à adaptação futura: foram percorridos anos até que irrompeu uma iconografia ilustradora de traços mais adequados, com menos preconceitos e clichés transferidos.

$\mathrm{Na}$ verdade, houve necessidade de um percurso diacrónico, articulado entre o olhar, o ver e o observar.

Numa primeira fase - o olhar - século XVI. A imagem solta ou em livros está ausente ${ }^{7}$.

O espanto inicial, escalonado entre o choque desconhecido e o entusiasmo pela novidade, descreve uma panóplia de sensações imediatas, eivadas de ecos espontâneos, onde a formalização dos conteúdos não tem lugar, nem significado.

Apesar da escrita estar a braços com a imensa tarefa de descrever novidades nunca vistas não recorre à imagem para facultar a inteligibilidade, processo que favorece presumíveis desajustes entre significantes e significados, em quem a lê deste lado.

Numa segunda fase - o ver - século XVII. O desenho aparece ${ }^{8}$.

A familiarização com a realidade circundante gera proximidades, onde o quotidiano joga efeitos continuados, com recurso a uma intelectualização apetrechada e alargada pelo traço linear.

A mutação nas formas de comunicação, com destaque para o risco inclui fauna e flora. A partir de agora, essa expressão suprime as fragilidades, quando a palavra não consegue exprimir nem transmitir os objectos envolventes.

Numa terceira fase - o observar - século XVIII. A ilustração científica é já uma realidade? .

Apesar das qualidades realistas que a escultura já trazia do gótico, só agora a representação a uma dimensão atinge uma densidade volumétrica desconhecida anteriormente. E isso, na medida mesma em que a pintura e o desenho avançam para um maior realismo científico.

Com efeito, paisagens, testemunhos sociais, peixes, plantas e rochas adquirem uma força nova, seja pelo traço linear, seja pela aguarela, feitos ao serviço do rigor requerido pelo universo teórico-experimental, na sua faceta comparativa.

Embora a discursividade entre as palavras e as coisas tivesse escalonado a aproximação entre os termos, é fora de dúvida que a lógica inerente foi percorrendo intervalos, entre a percepção imediatista e a inteligibilidade científica.

Entretanto e enquanto aquelas duas últimas fases não chegavam, foram os mapas, copiados e recopiados, que guardaram informações importantes sobre a natureza brasílica.

\footnotetext{
7 Pêro Vaz de Caminha (? - 1501), Gabriel Soares de Sousa (1540 - 1592), Pero de Magalhães Gandavo (? - 1579), Fernão Cardim (1542 - 1625).

${ }^{8}$ Exemplo significativo: Frei Cristóvão de Lisboa (? - 1652).

${ }^{9}$ Alexandre Rodrigues Ferreira (1756-1815) e companheiros.
} 
Quem já tem visto destas imagens, mas não está familiarizado com o corpus, poderá pensar que a colecção com representações naturais é grande. Mas a realidade é bem outra: a falsa sensação de quantidade resulta da beleza e qualidade dos originais, facultando várias reproduções dos pormenores.

A primeira colonização do Brasil só podia ter sido costeira: porque éramos poucos e continuávamos ainda a investir no Oriente, e porque a geografia local - com a Serra do Mar e outras «muralhas» - dificultava a penetração terras dentro.

Sendo assim, sabiam-se cartografar as áreas junto à costa, reconhecidas até do barco, mas tudo além continuava bastante desconhecido.

Não podendo ser retratado com base na realidade, o vazio territorial correspondia a uma série de lacunas pujantemente desconcertantes. E porque não senti-la como uma incapacidade simbólica devendo ser esconjurada?

Foi assim que num rasgo de originalidade, e para deleite estético dos vindouros, os cartógrafos pegaram nos seres naturais vislumbrados na terra perto do oceano ou dos rios e ocuparam, desde logo, o imenso continente a descobrir mais para dentro.

Brilhante, de facto.

Quando bem aproveitadas, há dificuldades que se tornam favoráveis à criatividade, pois permitem formas inteligentes de contornar os obstáculos e vias inovadoras para o futuro. $\mathrm{Na}$ verdade, esses desafios propiciam desbloqueamentos sucessivos, por meio de uma imaginação desafiante e sem peias, juntando tradições e misturando estilos.

No caso, encontros onde sobressaem por contraste: linhas delineando contornos, (efeitos de uma navegação mais costeira), linhas cruzando-se (efeitos da navegação mar fora) linhas abrindo lugar para iluminuras, pincelando uma fruta exótica ou uma animal exótico. Ao lado de belíssimas rodas dos ventos, também.

Gestos reveladores de uma configuração científica e epistemológica que acolhe a possibilidade de juntar cálculos matemáticos, servidos pelas exigências de um desenho preciso, e pinturas de seres vivos, mais espontâneas, livres e adequadas à especificidade destes entes.

Mestiçagem cultural, sem dúvida.

Dá a impressão que a iconografia faz prevalecer o real - os fenómenos impostos ao desenho - em desprimor do imaginado - os sonhos paradisíacos que a bibliografia continua a transmitir, apesar de tudo. Por isso, sentem-se movimentos e dinâmicas corporais.

Como os padrôes portugueses simbolizam marcas indeléveis de passagem-presença, os mapas apoderam-se simbolicamente da arara ou do ananás, os mais exuberantes para o olhar recém-chegado. E isso mesmo antes de haver quem vai encaixotá-los ou engaiolá-los, com destino ao mundo europeu. Comportamentos que mostram como as ciências modernas estiveram sempre ligadas à descoberta-conquista do mundo, incluindo os avanços, as ambiguidades e os subterfúgios coloniais.

Assim sendo, a territoralização do continente sul-americano resulta, quer da «realidade» simbólica projectada - pelos mapas -, quer do domínio efectivo "real-izado» - com armas -. Entre ambos, múltiplas actividades e múltiplos agentes, suportados pelas ciências antes do desembarque, e acalentadas pelas ciências terras além, numa penetração sob a égide do ouro e conseguida pouco a pouco.

Por outras palavras, a apropriação política portuguesa implicará, não só a conquista furando a Mata Atlântica ou a Floresta Amazónica, como o deleite provocado por um qualquer exotismo, num qualquer Gabinete de Curiosidades. 
Para as ciências modernas, por seu turno, implicará mapas, viagens filosóficas e descrição taxonómica, já no contexto científico de estudos desenvolvidos no interior de Jardins Botânicos e de Gabinetes de História Natural.

Por isso, as narrativas desmultiplicam-se em formas configurantes diversificadas, das palavras aos desenhos, dos livros a outros objectos.

$\mathrm{O}$ que irá permitir leituras de tipo gnoseológico, com mais-valias para uma melhor aproximação de como foram vividos e ilustrados os primeiros espantos e choques, a partir de desenhos esparsos naqueles documentos.

Mas não só. Pois também revelam outras tantas especificidades epocais - por restrições nuns casos (o índio não é homem) e amplificações noutros casos (o Reino Animal inclui o índio) - nos conteúdos inerentes ao conceito de Natureza.

$\mathrm{Na}$ verdade, a cartografia incluiu símbolos e ícones dos Três Reinos da Natureza: montanhas e rochas/mineral, plantas/vegetal, e bichos (que é diferente de animais mas integram as referências)/Animal, desde tempos remotos. Mas os selvagens indígenas de Vera Cruz, que na perspectiva de então não eram homens, aproximavam-se dos animais e como tal estavam em cenários naturais pouco antropologizados.

Contudo, os mapas integravam também representações de carácter etnográfico em que se isolava e destacava o europeu (e o oriental) da paisagem, e se lhe relevavam atributos etnográficos. De forma pouco consciente, os índios do Brasil acabaram por receber os atributos etnográficos que eram devidos aos europeus. É que os homens da Renascença, que concebiam e realizavam as cartas e que não os compreendiam como Homens-Pessoas, não tiveram outro remédio senão associar os atributos de Homens Europeus aos Seres Selvagens. Assim, parece que já nos primórdios do século XVI se começava a esboçar (aquilo que se repudiava e que só terá sido (?) resolvido no séc. XIX): os selvagens do Brasil por mais que se quisesse tinham atributos de Homens!

Com efeito, apesar das novidades do Renascimento e dos avanços introduzidos pelo Humanismo terem servido uma ideia de Homem diferente da tradição cristã mais genuína, importa ter presente quanto a ideia de Natureza permanecia diferente do que virá a revelar-se na Modernidade. Em síntese, o conceito de Natureza comportava, ainda, uma Criação una e universal: centrada na figura do Criador e dominada por um tipo de raciocínio marcadamente analógico.

Tal como as limitações geográficas reduziam a visão do planeta a cerca de um quarto por parte do Islão ${ }^{10}$, talvez o mesmo se possa entender na perspectiva da História Natural. As limitações geográficas testemunhavam certo desconhecimento dos variados objectos dos Três Reinos da História Natural. E até mesmo no espaço desconhecido as limitações impostas pela mentalidade medieval restringiam o reconhecimento de exemplares concretos e favoreciam a imaginação traduzida nas mais diversas aberrações e monstros que apenas existiram nos mapas então realizados.

A persistência desta mentalidade fechada documenta-se até muito tarde - tal como se pode ver nas ilustraçôes, desenhos e até mapas executados pelos séc. XV e XVI. Reveja-se as imagens típicas de seres acéfalos e monstros fantásticos atribuídas às geografias das regiôes etiópicas segundo Charles d'Angoulême nos Secrets de l'Histoire Naturalle 1 .

\footnotetext{
${ }^{10}$ Luís Filipe Barreto, Portugal en la Apertura del Mundo, 11.

${ }^{11}$ Luís Filipe Barreto, Portugal en la Apertura del Mundo, 11.
} 
No planisfério de Ebstorf (até 1240) a realidade é completamente distorcida pelas limitações técnicas e pelo recurso ao exagero dos marcos ou referências geográficas específicas. Neste planisfério, cidades, fortificaçōes, animais e até algumas plantas servem de ícones que permitiriam o reconhecimento fácil de determinadas regiōes, solução que viria a arrastar-se nalguma cartografia do Brasil.

No planisfério designado como «de Cantino» datado de 1502 (Biblioteca Estense, Modena) o abandono dos registos medievos é óbvio e apenas se realizam referências à flora e a fauna brasileira. A densidade da selva pode consistir numa alusão à Mata Atlântica, mas aparentemente nenhuma das espécies traduz a realidade. Já a fauna por distinta é pormenorizada embora limitada à espécie das araras.

O Mapa-Mundo datado de 1545 tem apenas registos toponímicos densíssimos. Não inclui alusão alguma específica ao Brasil, exceptuando-se algo parecido com um papagaio verde e um índio marcadamente heráldico, cujo escudo transporta as armas de Portugal, tal como os negros de África e alguns dos orientais. Os motivos vegetais são desprovidos de especificidade que permta o reconhecimento.

Por sua vez na Carta das Linhas Costeiras de Parte da Europa, África e América de Sebastião Lopes, 1558 (Biblioteca Britânica, Londres) as referências iconográficas llimitam-se a um índo na actividade do corte de madeira, actividade imposta pelo europeu, e algumas aves. As árvores são incaracterísticas, não traduzindo realidade alguma da botânica local.

No atlas de Diogo Homem de 1558 (Biblioteca Britânica, Londres) as representações da costa do Brasil incluem apenas indios caracterizados pelos respectivos atributos etnográficos em actos de canibalismo, caça, etc. As representações do reino vegetal limitam-se a formas pouco específicas que apenas contextualizam as actividades dos índios e decoram o atlas, Os animais, talvez felinos, replicam soluções e cânones heráldicos. E um dragão-montanha pode ser uma alusão aos fenómenos de vulcanismo do hemisfério Sul - Patagónia.

Em algumas plantas como o Mapa do Brasil, com a divisão das capitanias, como no Roteiro de Todos os Sinais (...) do Brasil, atribuído a Luís Teixeira (até 1586) (Biblioteca da Ajuda, Lisboa) não há referências iconográficas algumas, predominando a toponímia e os registos das linhas de água.

É curioso ver que nos registos de marinha, como no Livro de Marinharia de João de Lisboa (até 1560) (Arquivo Nacional da Torre do Tombo, Lisboa) os levantamentos da costa incluíam alguns registos dos maciços arbóreos, aqui de Moçambique, e o mesmo se pode destacar na observação cuidada de uma representação do cabo de Santo Agostinho, no Roteiro de todos os Sinais (...) do Brasil, atribuído a Luís Teixeira, até 1586 (Biblioteca da Ajuda, Lisboa)

Nalguns exemplares posteriores como a Carta Atlântica de Luís Teixeira datável até 1600 (Biblioteca Nacional Central, Florença) não há registos alguns a espécies brasileiras, direccionando-se a maior parte dos motivos decorativos como palmeiras e aglomerados fortificados à Costa de África, bem como outros que patenteavam a devoção religiosa cristã dos aborígenes.

No planisfério do Atlas - Comografia de João Baptista Lavanha e Luís Teixeira, até 1597-1612 (Biblioteca Reall, Turín) não há registos iconográficos específicos aos Três Reinos, senão alusões a manchas densamente arborizadas, montanhas e rios caudalosos. 
Podem destacar-se publicações de trabalhos de portugueses nas quais as representações gráficas de exemplares botânicos acompanham descriçōes pormenorizadas. Cite-se apenas o Tratado das Drogas e Medicinas das Índias Orientais de Cristóvão da Costa, Burgos, 1578

E em paralelo refira-se as representações vegetais na tradução italiana da Asia de João de Barros (1563). Estas cumprindo funçōes distintas das expectáveis no âmbito de registos mais pormenorizados

Sendo vasta a cartografia com registos do Brasil que não tem imagens dos Três Reinos;

Sendo a cartografia que inclui imagens dos Três Reinos se refere apenas a algumas representaçôes pouco fidedignas e a muito poucas que permitem a identificação através de caracteres fisionómicos realistas (talvez as da capivara e a das araras;

Neste contexto, as referências iconográficas limitadas a um tão reduzido número de espécies podem indiciar pouco interesse no contexto da Cartografia (a não ser numa perspectiva iconográfica) e podem indiciar ainda pouco interesse pela História Natural, dado o ínfimo número de espécies face à variedade botânica, animal e mineral a que os portugueses tinham sido sujeitos no decurso das viagens e colonização.

Concluindo, também por esta via, somos levados à conclusão de quanto foi notória a novidade biblioiconográfica - emergência de uma História Natural no contexto luso-brasileiro - trazida pela viagem filosófica de Alexandre Rodrigues Ferreira e seus companheiros.

\section{BIBLIOGRAFIA}

\section{Fontes}

Alexandre Rodrigues Ferreira a quem Acompanhárão os Desenhadores Joseph Joachim Freire e Joachim Joseph Codina E o Jardineiro Botanico Joaquim Agostinho de Cabo, «Roteiro Das Viagens que fez Pelas Capitanias Do Pará, Rio Negro, Mato grosso e Cuiabá». Lisboa, Biblioteca da Ajuda, c. 54-XI27, nº15, na.1783, ms..

Antonil, André João - Cultura e Opulência do Brasil. Belo Horizonte, Ed. Itatiaia, 1997.

BAP, «Solicitação de 12 de Setembro de 1795». Códice 622, apud Arthur Cezar Ferreira Reis, "O Jardim Botânico de Belém». In "Boletim do Museu Nacional. Botânica», Rio de Janeiro, (7), Set. 1946, p. 14.

BRANDĀo, Ambrósio Fernandes - Diálogos das Grandezas do Brasil. Rio de Janeiro, Dois Mundos Editora, [1943].

Breves instrucçöes aos correspondentes da Academia das Sciencias de Lisboa sobre as remessas dos productos e notícias pertencentes à Historia da Natureza para FORMAR HUM Museo Nacional. Lisboa, Regia Officina Typographica, 1781 .

Brotero, Felix de Avellar - "Catalogo geral de todas as Plantas do Real Jardim Botanico d Ajuda distribuidas segundo o Systema de Linneo, da edição do D. ${ }^{\text {or }}$ Wildennow », Lisboa, Instituto Superior de Agronomia. Biblioteca, s.d., ms..

Caldas, António Pereira de Sousa - Ode ao homem selvagem. Obras poeticas. Coimbra, 1836.

Caminha, Pêro Vaz de - Carta a el-rei dom Manuel sobre o achamento do Brasil (1 de Maio de 1500). Lisboa, Imprensa Nacional-Casa da Moeda, 1974. 
CARDIM, Fernão - Fernão Cardim, Tratados da Terra e da Gente do Brasil. Belo Horizonte-São Paulo, Editora Itatiaia-Editora da Universidade de São Paulo ,1980.

Coisas Notáveis do Brasil. vol. I, Rio de Janeiro, Instituto Nacional do Livro-Ministério da Educação e Cultura, 1966.

DURĀo, Frei José de Santa Rita - Caramuru, Lisboa, Imprensa Nacional, 1836.

«Expedição Filosofica do Pará de que hé Naturalista o Doutor Alexandre Rodrigues Ferreira, os Riscadores, José Codina, e José Joaquim Freire, e Agostinho do Cabo, Jardineiro Botanico, o qual partio aos 14 de julho de 1783. Relação do que levou o ditto Naturalista deste Real Gabinete de Ajuda», Lisboa, Museu Bocage, Maço 5, no 7.

Ferreira, Alexandre Rodrigues - Viagem Filosófica pelas capitanias de Grāo Pará, Rio Negro, Mato Grosso e Cuiabá (1783-1792). Texto - 2 vols., Rio de Janeiro, Conselho Federal de Cultura, 1972-1974. Gravuras - 2 vols., São Paulo, Editora Monumental, 1971.

-Florae Fluminensis de Fr. José Mariano da Conceição Veloso. Documentos. Rio de Janeiro, Arquivo Nacional, 1961.

Gama, José Basílio da - O Uraguay. Rio de Janeiro, Livraria Agir Editôra, 1941.

Gandavo, Pero de Magalhães - Tratado da Terra do Brasil. História da Província de Santa Cruz. Belo Horizonte, Editora Itatiaia-Editora da Universidade de São Paulo, 1980.

LisboA, Frei Cristóvão de - Historia dos animaes e arvores do Maranhão. Lisboa, Arquivo Histórico Ultramarino e Centro de Estudos Históricos Ultramarinos, 1967.

SEPP, Padre António - Viagem às Missões Jesuiticas e Trabalhos Apostólicos. São Paulo, Livraria Martins Editora-Editora da Universidade de São Paulo, 1972 (A Viagem, primeiro texto sobre estas reduções, é um conjunto de cartas quase todas enviadas pelo jesuíta tirolês ao irmão. Os Trabalhos incluem a fundação da Redução de São João Batista).

S,L., S.D., MSI.II, 33,17,14 apud Leopoldo Collor Jobim, Os Jardins Botânicos e o fomentismo português no Brasil, «Sociedade Brasileira de Pesquisa Histórica», São Paulo, 1984.

SouSA, Gabriel Soares de - Tratado descritivo do Brasil em 1587. São Paulo, Companhia Editora Nacional, 1987.

VANDELl, Domingos, «Relaçao da origem, e estado prezente do Real Jardim Botanico, Laboratório Chymico, Muséu de Historia Natural, e Caza do Risco», Lisboa, Arquivo Nacional da Torre do Tombo, Archivo do Ministério do Reino, Maço 444, c. 1.54.103, s.d., ms..

VANDELli, Domingos, «Memorias Inéditas», Lisboa, Biblioteca da Ajuda, c .54-V-14, s.d., ms.

\section{Outros}

Almeida, Luís Ferrand de - Páginas Dispersas. Estudos de História Moderna de Portugal. Coimbra, Faculdade de Letras, 1995.

Alves, Ana Maria - As Entradas Régias Portuguesas: Uma visão de conjunto., Livros Horizonte, Lisboa.

AÑon, Carmen e SANCHO, José Luís (Ed.) - Jardín y Naturaleza en el reinado de Felipe II. Sociedad Estatal para la Commemoración de Los Centenarios de Felipe II (1998) y Carlos V (2000), 1998.

Barreto, Luís Filipe - Portugal en la Apertura del Mundo. Ed. Comissão Nacional para as Comemorações dos Descobrimentos Portugueses, Lisboa,

Castel-Branco Pereira, João (coord.) - Exotica: Os descobrimentos Portugueses e as Câmaras de Maravilhas do Renascimento. Museu Calouste Gulbenkian, 2001.

Domingues, Heloísa Maria Bertol Domingues, El Jardin Botánico do Rio de Janeiro y los Intercambios Internacionales. Comunicação ao Coloquio Materia Médica, Terapéutica y Farmacia Intercontinental, Puebla, 1996. 
FARIA, Miguel Figueira - A Imagem Útil. Universidade Autónoma Editora. Lisboa. 2001.

Gonçalves, Maria da Conceição Osório Dias - O Índio do Brasil na Literatura Portuguesa dos séculos XVI, XVII e XVIII. Coimbra, 1961, Separata de Brasilia, vol. XI.

Holanda, Sérgio Buarque de - Visão do Paraíso. Os motivos edênicos no descobrimento e colonizaçāo do Brasil. $4^{a}$ ed., São Paulo, Companhia Editora Nacional, 1985.

Janeira, Ana Luísa - Humanismo. Logocentrismo. Etnocentrismo. «Revista Portuguesa de Filosofia», Braga, 38 (4) Out.-Dez. 1982, 221-240. Actas do $1^{\circ}$ Congresso Luso-Brasileiro de Filosofia.

Janeira, Ana Luísa - Viagem filosófica pelo espaço-tempo dos Jardins Botânicos. in Ana Maria Alfonso-Goldfarb, Carlos A. Maia (orgs.), «História da ciência: o mapa do conhecimento», São Paulo, Editora da Universidade de São Paulo, 1995, pp. 543-550.

Janeira, Ana Luísa; Mourāo, José Augusto; Guedes, Maria Estela - A Paixão do Coleccionador: Espaços de Colecção. In «Encontro sobre Alcipe e as Luzes», Lisboa, Fundação das Casas de Fronteira e Alorna, 1997, pp. 75-87.

Janeira, Ana Luísa; ForTes, Mário - Floras do Novo Mundo. Curiosidades e Recursos. Actas do $5 \circ$ Encontro de Évora de História e Filosofia das Ciências, Évora, Universidade de Évora (no prelo).

JANEIRA, Ana Luísa (org.) - Gabinete de Curiosidades. Lisboa, Centro Interdisciplinar de Ciência, Tecnologia e Sociedade da Universidade de Lisboa (CICTSUL), 1999.

JoBim, Leopoldo Collor - Os Jardins Botânicos e o fomentismo português no Brasil, «Sociedade Brasileira de Pesquisa Histórica», São Paulo, 1984.

LEITE, Serafim - Artes e Oficios dos jesuitas no Brasil (1549-1760). Lisboa-Rio de Janeiro, Ediçôes BrotériaLivros de Portugal, 1953.

Silva, Maria Beatriz Nizza da - A Cultura Luso-Brasileira. Da Reforma da Universidade à independência do Brasil. Lisboa, Editorial Estampa, 1999.

SIMON, William Joel Simon - Scientific Expeditions in the Portuguese Overseas Territories (1783-1808) and the role of Lisbon in the Intelectual-Scientific Community of the late Eighteenth Century. Lisboa, Instituto de Investigação Científica Tropical, 1983.

Thevet, André - Le Brésil d'André Thevet. Les Singuralités de la France Antarctique. Paris, Editions Chandeigne, 1997. 
(Página deixada propositadamente em branco) 


\section{Colecçãa \\ 2 Ciências e Culturas Caimbra 2006}

